\title{
Compact Dual-Band Bandpass Filter Using U-Shaped Stepped-Impedance Resonators with Parallel Coupled Structures
}

\author{
Gyuje Sung*
}

\begin{abstract}
This paper proposes a dual-band bandpass filter using stepped-impedance resonators (SIRs) with parallel coupled structures. The proposed filter adopts U-shaped SIRs with parallel coupled lines (PCLs) that have interdigital and comb-line shorted ends. The central PCLs build an upper passband and a transmission zero, and the two U-shaped SIRs build a lower passband. Four resonators and coupling structures are theoretically analyzed to derive its scattering parameters. A novel dual-band bandpass filter is designed and fabricated using the induced scattering characteristics. The measured results show that the fabricated dual-band bandpass filter has an insertion loss of less than $1.02 \mathrm{~dB}$ in the lower band of $2.45 \mathrm{GHz}$ and of $3.01 \mathrm{~dB}$ in the upper band of $3.42 \mathrm{GHz}$, and a band-to-band isolation of more than $40 \mathrm{~dB}$, from 3.14 to $3.2 \mathrm{GHz}$.
\end{abstract}

Key Words: Bandpass Filter, Dual-Band, Notched Filter, Parallel-Coupled Lines, Stepped-Impedance Resonators.

\section{INTRODUCTION}

Various wireless/mobile communication systems require multi-service and/or multi-band applications to overcome expansion in the quantity of communication traffics. Microwave multiband bandpass filters (BPFs) are important and essential components to satisfy such demands. To lower the fabrication cost and raise the performance, microstrip multi-band BPFs have been developed with compact sizes, large out-of-band rejection, and high selectivity.

Many microstrip multi-band BPFs have been implemented using multi-mode resonators (MMRs), coupled lines (CLs), etc. Some of MMR filters used square ring loaded resonator [1], stub-loaded quad-mode resonator (QMR) [2-5], and a QMR with source-load coupling [6]. A single QMR with parallel coupling microstrip lines was also introduced to implement dual-band BPFs [7]. Compact dual-band interdigital BPF has been achieved by using hybrid resonators with series and shunt resonances [8]. Some authors have proposed to design dual/triple-band filters using asymmetrical CLs [9] or using CLs and grounded stepped impedance resonators (SIRs) [10]. Recently, the dual-band BPFs with high selectivity have been introduced using two different resonators [11], and U-shaped resonators [12]. Composite coupling structure for coplanar waveguide/microstrip [13] and complementary split-ring resonators with complementary spiral resonator [14] have been adopted in the development of dual-band BPFs.

In this paper, we present the design of a dual-band BPF us-

Manuscript received September 8, 2017 ; Revised December 7, 2017 ; Accepted January 5, 2018. (ID No. 20170908-050J)

Department of Electrical and Electronic Engineering and IITC, Hankyong National University, Ansung, Korea.

"Corresponding Author: Gyuje Sung (e-mail: gjsung@hknu.ac.kr)

This is an Open-Access article distributed under the terms of the Creative Commons Attribution Non-Commercial License (http://creativecommons.org/licenses/by-nc/4.0) which permits unrestricted non-commercial use, distribution, and reproduction in any medium, provided the original work is properly cited.

(c) Copyright The Korean Institute of Electromagnetic Engineering and Science. All Rights Reserved. 
ing SIRs with parallel coupled structures. The even/odd-mode input admittances of the proposed structures are derived and the transfer function is theoretically proved. The simulated and measured results of the proposed dual-band BPF are shown to be in good agreement.

\section{ANALYSIS}

The proposed dual-band BPF as shown in Fig. 1 has a symmetrical structure, and even/odd-mode analysis can be used to derive the even/odd-mode input admittances and transfer function. From the equivalent circuit of the proposed structure in Fig. 2 [15], the input admittances of the proposed dual-band $\mathrm{BPF}$ are as follows:

$$
Y_{i n, i}=j \omega C_{01} \frac{\left(Y_{1 a}-Y_{c p l, i} \tan \theta_{1 a}\right) Y_{1 a}\left(Y_{c p l, i}+Y_{1 a} \tan \theta_{1 a}\right)}{\omega C_{01}\left(Y_{1 a}-Y_{c p l, i} \tan \theta_{1 a}\right)+Y_{1 a}\left(Y_{c p l, i}+Y_{1 a} \tan \theta_{1 a}\right)}
$$

where the subscript $i$ represents $e$ for even-mode and $o$ for oddmode and $Y_{\text {cpli }}$ is

$$
Y_{c p l, e}=Y_{12} \frac{Y_{2, e}\left(\tan \theta_{2}-\cot \theta_{1}\right)+Y_{12} \tan \theta_{1}}{Y_{12}-Y_{2, e}\left(\tan \theta_{2}-\cot \theta_{1}\right) \tan \theta_{1}}-Y_{1} \cot \theta_{1}
$$

or

$$
Y_{c p l, o}=Y_{12} \frac{Y_{2, o}\left(\tan \theta_{2}-\cot \theta_{1}\right)+Y_{12} \tan \theta_{1}}{Y_{12}-Y_{2, o}\left(\tan \theta_{2}-\cot \theta_{1}\right) \tan \theta_{1}}-Y_{1} \cot \theta_{1}
$$

$Y_{\text {cple }}$ is the even-mode input admittance at node 1 as shown in Fig. 2(a), and $Y_{c p l o}$ is the odd-mode one as shown in Fig. 2(b).

Under the even-mode excitation of Fig. 2(a), the resonance condition can be derived by setting $Y_{\text {in, }}=0$. Two even-mode resonant frequencies, $f_{e 1}$ and $f_{e 2}$, are derived by following equations.

$$
\begin{gathered}
\left(Y_{1 a} \tan \theta_{1 a}-Y_{1} \cot \theta_{1}\right)\left(Y_{1 a}+Y_{2, e}\left(1-\tan \theta_{1} \tan \theta_{2}\right)\right) \\
+Y_{12}\left(Y_{12} \tan \theta_{1}-Y_{2, e}\left(\cot \theta_{1}-\tan \theta_{2}\right)\right)=0
\end{gathered}
$$

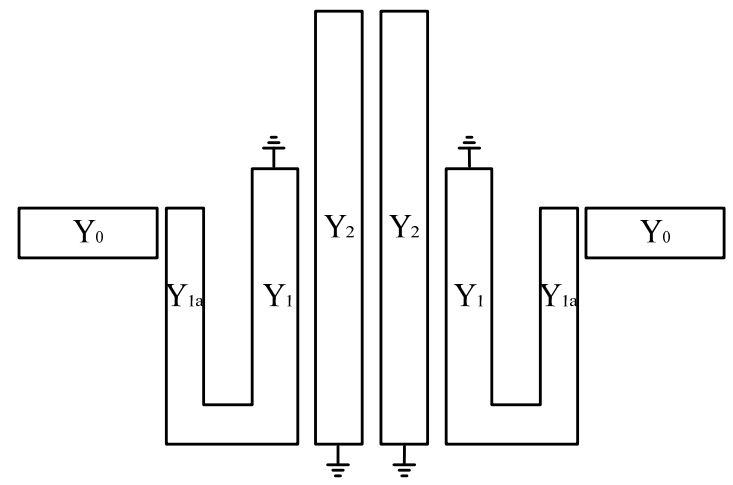

Fig. 1. Schematic diagram of the proposed dual-band BPF.

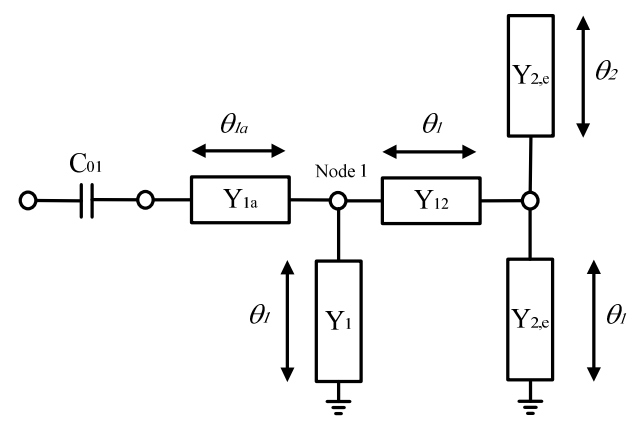

(a)

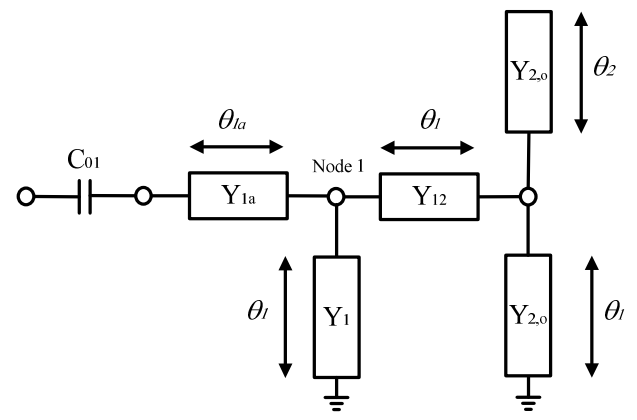

(b)

Fig. 2. Equivalent circuit of the proposed dual-band BPF: (a) the even mode and (b) the odd mode.

Under the odd-mode excitation of Fig. 2(b), two resonant frequencies, $f_{01}$ and $f_{02}$, can be produced by setting $Y_{i n, 0}=0$ as follows:

$$
\begin{aligned}
& \left(Y_{1 a} \tan \theta_{1 a}-Y_{1} \cot \theta_{1}\right)\left(Y_{1 a}+Y_{2, o}\left(1-\tan \theta_{1} \tan \theta_{2}\right)\right) \\
& +Y_{12}\left(Y_{12} \tan \theta_{1}-Y_{2, o}\left(\cot \theta_{1}-\tan \theta_{2}\right)\right)=0
\end{aligned}
$$

The transfer function, $S_{21}$, can be expressed as

$$
S_{21}=\frac{\left(Y_{i n, o}-Y_{i n, e}\right) Y_{0}}{\left(Y_{i n, e}+Y_{0}\right)\left(Y_{i n, o}+Y_{0}\right)}
$$

where $Y_{0}$ is the admittance of the input/output port. A transmission zero is created when $S_{21}=0$, i.e. ,

$$
Y_{i n, e}=Y_{i n, o}
$$

Therefore, a transmission zero is created when

$$
\tan \theta_{2}=\cot \theta_{1}
$$

Fig. 3 describes the resonant characteristics of the proposed BPF with weak input/output coupling against the electrical lengths $\theta_{1}, \theta_{1 \text { a }}$, and $\theta_{2}$, respectively. In Fig. 3(a), all resonant frequencies and transmission zero frequency shift down evenly as the electrical length, $\theta_{1}$ increases because $\theta_{1}$ is the electrical length of interdigital coupled lines. Fig. 3(b) shows that the varia- 


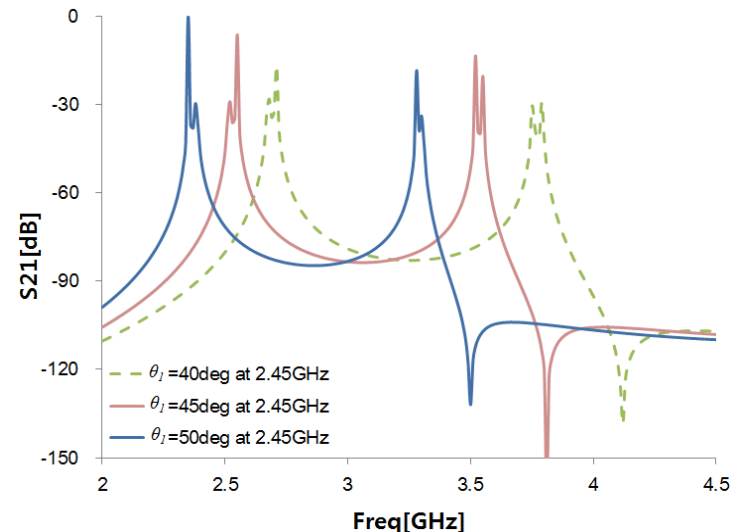

(a)

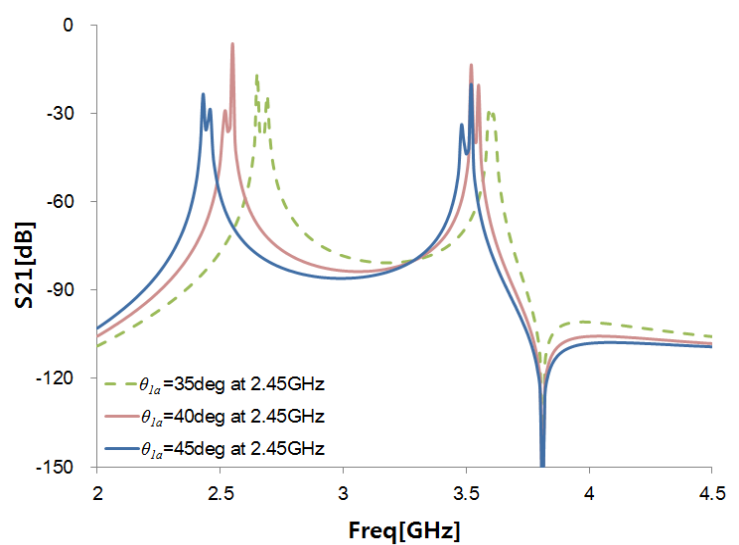

(b)

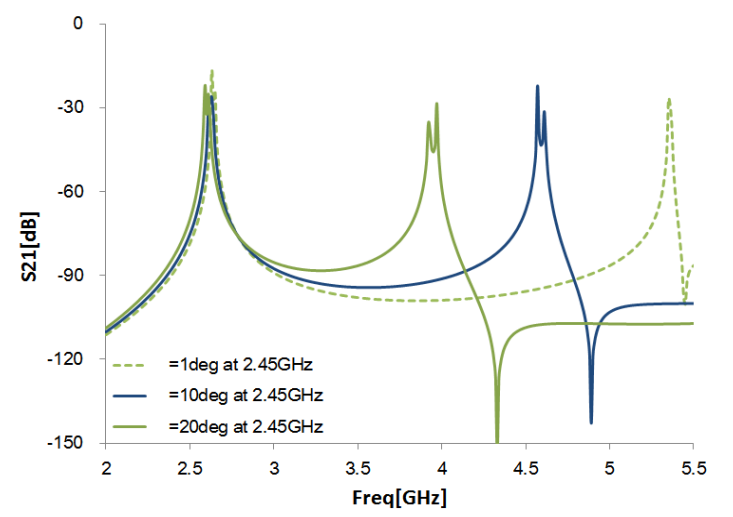

(c)

Fig. 3. Resonant characteristics of the proposed BPF of weak coupling against the electrical length: (a) $\theta_{1}\left(\theta_{1 \mathrm{a}}=40^{\circ}, \theta_{2}=25^{\circ}\right)$, (b) $\theta_{1 \mathrm{a}}\left(\theta_{1}=45^{\circ}, \theta_{2}=25^{\circ}\right)$, and (c) $\theta_{2}\left(\theta_{1 \mathrm{a}}=40^{\circ}, \theta_{1}=45^{\circ}\right)$.

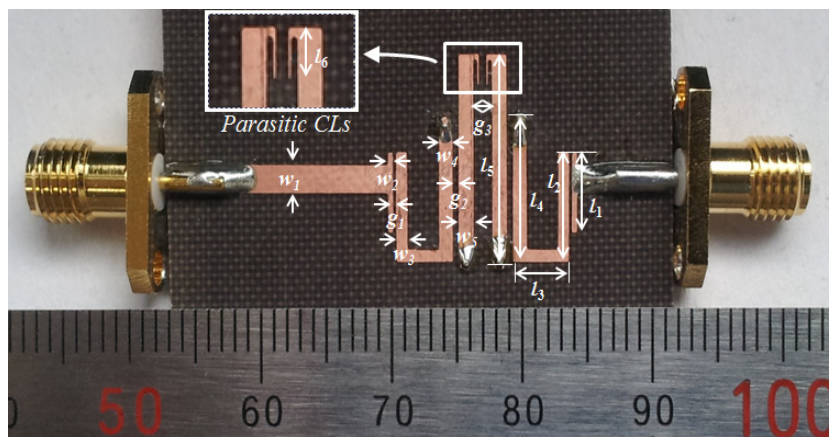

Fig. 4. Photograph of the fabricated dual-band BPF. tion of electrical lengths $\theta_{1 \mathrm{a}}$ changes two lower resonant frequencies, while the transmission zero frequency keeps constant. $\theta_{2}$ makes the two upper resonant frequencies and transmission zero frequency shift as shown in Fig. 3(c). From the simulation results, we found out that the central parallel CLs build an upper passband and a transmission zero, and two U-shaped SIRs build a lower passband.

\section{DESIGN AND FABRICATION}

The proposed dual-band BPF was implemented on a Taconic TLX-8 dielectric substrate with a dielectric constant of 2.55 , thickness of $0.787 \mathrm{~mm}$, and loss tangent of 0.0012 . The fabricated dual-band BPF shown in Fig. 4 comprises shorted SIRs with interdigital and comb-line type parallel coupled structures. To move the notch frequency, we need to change the lengths of central coupled lines, $\theta_{1}$ and $\theta_{2}$. But varying them, two passbands also vary as shown in Fig. 3. In order to put a notch frequency between two passbands for minimizing the variation of the existing passbands, the parasitic coupled lines were adopted between the main coupled lines as shown in Fig. 4. The effect of the parasitic coupled lines is shown in Fig. 5. The longer the length of the parasitic CLs, the lower the notch frequency. Through the design equation from the previous chapter and simulation by ANSYS HFSS, the dimensions for this dualband BPF were established as follows: $w_{1}=2.2 \mathrm{~mm}, w_{2}=0.5$ $\mathrm{mm}, w_{3}=1.0 \mathrm{~mm}, w_{4}=1.2 \mathrm{~mm}, w_{5}=1.25 \mathrm{~mm}, l_{1}=5.9 \mathrm{~mm}, l_{2}=$ $8.0 \mathrm{~mm}, l_{3}=4.22 \mathrm{~mm}, l_{4}=10.0 \mathrm{~mm}, l_{5}=15.0 \mathrm{~mm}, l_{6}=2.38 \mathrm{~mm}$, $g_{1}=0.13 \mathrm{~mm}, g_{2}=0.35 \mathrm{~mm}$, and $g_{3}=1.3 \mathrm{~mm}$. The overall size of the filter is $14 \times 15 \mathrm{~mm}^{2}$, approximately $0.17 \lambda_{g} \times 0.18 \lambda_{g}, \lambda_{g}$ being the guided wavelength at the center frequency of the first passband. The measurements were performed using an Anritsu $37347 \mathrm{C}$ vector network analyzer. The simulated and measured results of the fabricated filter are shown in Fig. 6, and show good agreement. For the first passband of $2.45 \mathrm{GHz}$, the insertion loss is less than $1.02 \mathrm{~dB}$. For the second passband of 3.42 $\mathrm{GHz}$, the measured insertion loss is less than $3.01 \mathrm{~dB}$; the

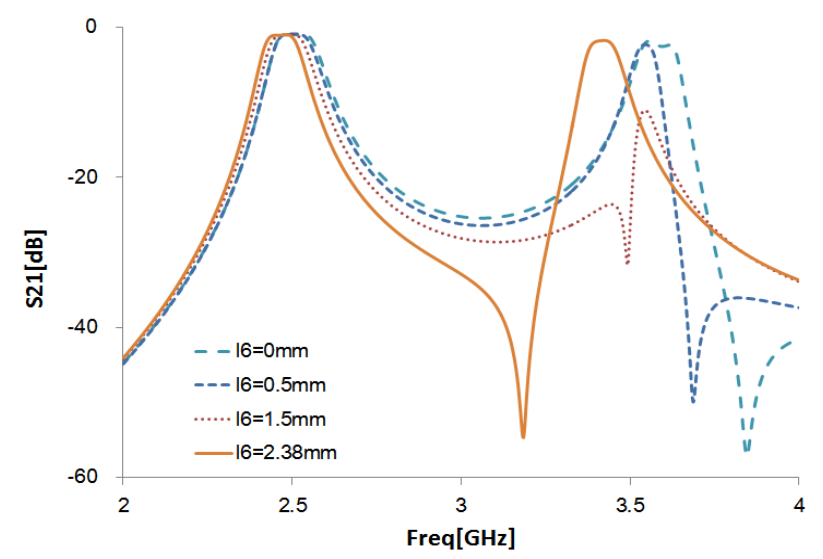

Fig. 5. Effect of the parasitic coupled lines. 
Table 1. Comparison of dual-band BPFs

\begin{tabular}{lccccc}
\hline & Ref. [7] & Ref. [5] & Ref. [11] & Ref. [14] & This work \\
\hline Center frequency (GHz) & $1.96,5.58$ & $2.5,5.8$ & $2.4,5.2$ & $3.84,4.96$ & $2.45,3.42$ \\
Fractional BW (\%) & $57.1,20.8$ & - & $7.4,4$ & $6.7,5.3$ & $3.7,1.5$ \\
Isolation (dB) & $>30$ & $>30$ & $>15$ & $>35$ & $>40$ \\
Insertion loss (dB) & $0.52,1.1$ & $0.77,1.56$ & $0.3,0.8$ & $1.65,3.33$ & $1.02,3.01$ \\
Filter size $\left(\lambda_{g}{ }^{2}\right)$ & $0.4 \times 0.05$ & $0.15 \times 0.37$ & $0.2 \times 0.2$ & $0.12 \times 0.18$ & $0.17 \times 0.18$ \\
\hline
\end{tabular}

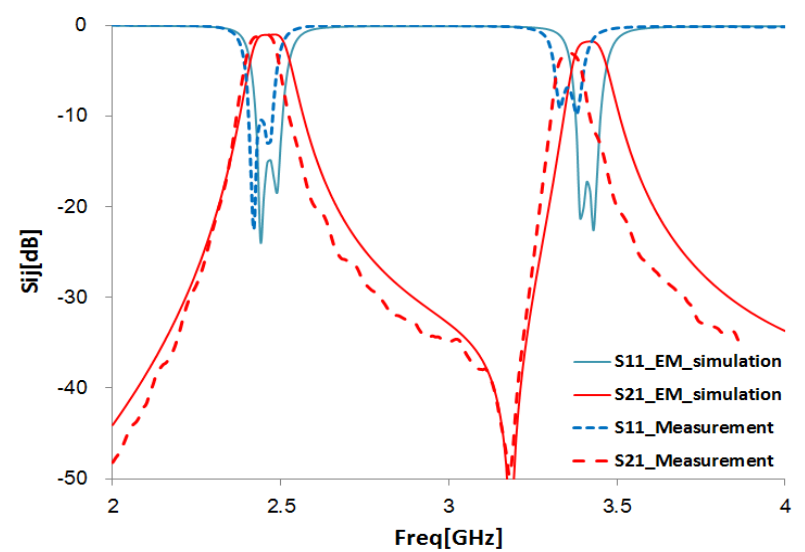

Fig. 6. Simulated and measured frequency responses of the dualband BPF.

band-to-band isolation is more than $40 \mathrm{~dB}$ from 3.14-3.2 $\mathrm{GHz}$. The difference of the insertion loss of the simulated and measured results in the second band seems to be caused by the radiation loss and mismatching in the input and output port. Table 1 summarizes the performance comparison of the proposed filter with some previously reported ones. As shown, the fabricated dual-band BPF has higher band-to-band isolation than those proposed in the works under comparison, and its size is more compact than that proposed in [5] and [11].

\section{CONCLUSION}

A dual-band BPF using U-shaped SIRs with PCLs having interdigital and comb-line shorted ends is proposed in this study. The proposed structure is theoretically analyzed to derive its scattering parameters. U-shaped SIRs with PCLs achieve dual-band characteristics. A proposed dual-band BPF was designed and fabricated and good agreement was found between the measured and simulated results. This result validates the design concept. The fabricated filter shows high band-to-band isolation and a compact size.

\section{REFERENCES}

[1] H. Liu, B. Ren, X. Guan, J. Lei, and S. Li, "Compact dual- band bandpass filter using quadruple-mode square ring loaded resonator (SRLR)," IEEE Microwave and Wireless Components Letters, vol. 23, no. 4, pp. 181-183, 2013.

[2] S. J. Sun, T. Su, K. Deng, B. Wu, and C. H. Liang, "Compact microstrip dual-band bandpass filter using a novel stub-loaded quad-mode resonator," IEEE Microwave and Wireless Components Letters, vol. 23, no. 9, pp. 465-467, 2013.

[3] J. Xu, W. Wu, and C. Miao, "Compact microstrip dual/tri-/quad-band bandpass filter using open stubs loaded shorted stepped-impedance resonator," IEEE Transactions on Microwave Theory and Techniques, vol. 61, no. 9, pp. 3187-3199, 2013.

[4] L. Gao, X. Y. Zhang, B. J. Hu, and Q. Xue, "Novel multistub loaded resonators and their applications to various bandpass filters," IEEE Transactions on Microwave Theory and Techniques, vol. 62, no. 5, pp. 1162-1172, 2014.

[5] F. Wei, Y. J. Guo, P. Y. Qin, and X. W. Shi, "Compact balanced dual- and tri-band bandpass filters based on stub loaded resonators," IEEE Microwave and Wireless Components Letters, vol. 25, no. 2, pp. 76-78, 2015.

[6] L. Gao and X. Y. Zhang, "High-selectivity dual-band bandpass filter using a quad-mode resonator with sourceload coupling," IEEE Microwave and Wireless Components Letters, vol. 25, no. 9, pp. 474-476, 2015.

[7] J. Xu, W. Wu, and C. Miao, "Compact and sharp skirts microstrip dual-mode dual-band bandpass filter using a single quadruple-mode resonator (QMR)," IEEE Transactions on Microwave Theory and Techniques, vol. 61, no. 3, pp. 1104-1113, 2013.

[8] Y. H. Cho, X. G, Wang, and S. W. Yun, "Design of dualband interdigital bandpass filters using both series and shunt resonators," IEEE Microwave and Wireless Components Letters, vol. 22, no. 3, pp. 111-113, 2013.

[9] Y. H. Cho and S. W. Yun, "Design of balanced dual-band bandpass filters using asymmetrical coupled lines," IEEE Transactions on Microwave Theory and Techniques, vol. 61, no. 8, pp. 2814-2820, 2013.

[10] Y. Mo, K. Song, and Y. Fan, "Miniaturized triple-band bandpass filter using coupled lines and grounded stepped 
impedance resonators," IEEE Microwave and Wireless Components Letters, vol. 24, no. 5, pp. 333-335, 2014.

[11] S. Lv, Y. Ge, and W. Zhang, "Compact high-selectivity dual/tri-band bandpass filters for WLAN applications," Progress In Electromagnetics Research C, vol. 61, pp. 131138, 2016.

[12] E. Ogbodo, Y. Wang, and K. S. Yeo, "Microstrip dualband bandpass filter using U-shaped resonators," Progress In Electromagnetics Research Letters, vol. 59, pp. 1-6, 2016.

[13] J. Wang and P. Gao, "Dual-band bandpass filter using composite coupling structure for CPW/microstrip," Pro-

\section{Gyuje Sung}

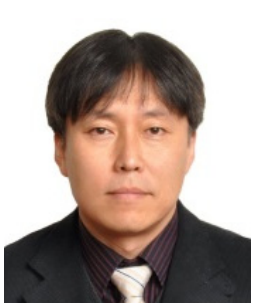

received his B.S., M.S., and Ph.D. degrees in electrical engineering from Sogang University, Seoul, Korea in 1986, 1988, and 1998, respectively. From 1988 to 1993, he worked at Agency for defense Development, Daejeon, Korea. Since 1998, he has been with Hankyong National University, Ansung, Korea, where he is a professor of the Department of Electronic and Electrical Engineering. His research interests include analog circuits, RF and microwave circuits, and antennas. gress In Electromagnetics Research Letters, vol. 58, pp. 53-57, 2016.

[14] H. Y. Gao, Z. X. Tang, X. Cao, and Y. Q. Wu, "Compact dual-band SIW filter with CSRRS and complementary spiral resonators," Microwave and Optical Technology Letters, vol. 58, no. 1, pp. 1-4, 2016.

[15] G. J. Sung, D. H. Ye, and B. Kim, "Equivalent circuit design of multilayer parallel-coupled line filter," in Proceedings of IEEE Radio and Wireless Conference, Atlanta, GA, 2004, pp. 239-241. 